\section{Neumomediastino espontáneo. A propósito de un caso}

\author{
Sr. Director:
}

El enfisema mediastínico o neumomediastino se define por la presencia de aire en el mediastino. El neumomediastino aparece con escasa frecuencia, suele ser secundario a traumatismos, maniobras iatrogénicas y en otras ocasiones no existe una causa desencadenante evidente, considerándose entonces espontáneo, siendo su patogenia el aumento de gradiante de presión alveolointersticial no iatrógeno ${ }^{1-3}$.

En el caso que a continuación se describe se diagnosticó de neumomediastino por confirmación radiológica de aire libre en mediastino.

Varón de 21 años con antecedentes de polinosis y epigastralgia. Presentó un cuadro de orquiepididimitis aguda que pese al tratamiento con antiinflamatorios y antibióticos requirió ingreso hospitalario durante 5 días. Al tercer día del ingreso presentó de manera brusca en la cama dolor retroesternal opresivo intenso irradiado a cuello, mandíbula y brazo izquierdo acompañado de intensa sudoración y disnea cediendo espontáneamente a las dos horas. A los dos días del alta acude a la consulta por crepitación en cuello. En la exploración física presentaba crepitación en región cervical izquierda. Auscultación cardiaca: crepitación sincrónica con el latido cardiaco. Resto de exploración normal. La radiografía de tórax mostraba una línea radiotransparente en borde cardiaco izquierdo y un enfisema subcutáneo en región cervical izquierda (Fig.1). La evolución fue favorable, resolviéndose mediante tratamiento conservador en ocho días.

\section{DISCUSIÓN}

El neumomediastino se caracteriza por la presencia de aire en el espacio mediastínico. Su pa- togenia fue descrita por Macklin y Macklin en 1944; el aumento de la presión intraalveolar produce la rotura de algunos alveolos, escapando el aire y disecando el espacio intersticial perivascular hasta llegar al mediastino $^{3}$. El neumomediastino se clasifica en traumático, iatrógenico y espontáneo; la cuarta parte de los espontáneos son idiopáticos, el resto secundarios a asma bronquial, tosferina, obstrucciones respiratorias, inhalación de cocaína, tras maniobra de valsalva, esfuerzo físico o respiraciones forzadas (nuestro paciente debido al intenso dolor que presentaba por la orquiepididimitis realizaba respiraciones profundas pudiendo ser ésta la causa del neumomediastino) ${ }^{1-5}$. Clinicamente se caracteriza por dolor retroesternal brusco de características pleuríticas irradiado a brazo izquierdo, cuello, espalda; así como disnea, cianosis y sensación de tumefacción en cuello. Los signos clínicos más comunes son el enfisema subcutáneo cervical $(70 \%)$ y la crepitación sincrónica con el latido 


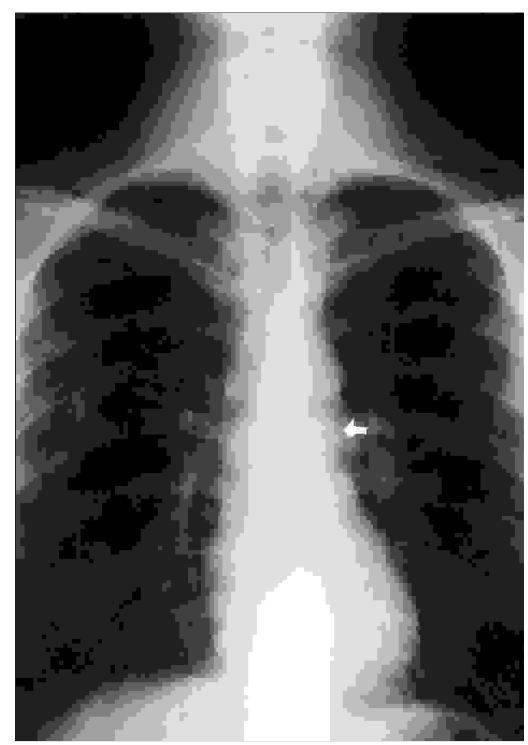

Figura 1

Radiografía AP donde se observa una línea radiotransparente en el borde cardiaco izquierdo (flecha) así como enfisema subcutáneo cervical.

\section{BIBLIOGRAFÍA}

1. Shyamsunder AK, Gyaw SM. Pneumomediastinum: The valsalva crunch Md Med J 1999; 48 (6): 229-302.

2. Toral Marin J, Del Castillo Otero D, Hurtado Ayuso JE, Calderón Osuna E. Neumomediastino espontáneo como complicación de una crisis asmática. Rev Clin Esp. 1999; 199 (2): 78-80.

3. Blanquer J, Chiner E, Nuñez C, Blanquer R, Muñoz J. Neumomediastino espontáneo del adulto. Rev Clin Esp 1990; 187: 22-4. 1984; 144: 1447-53.

4. Calvo Romero JM. Neumomediastino espontáneo y fibrosis pulmonar idiopática. An Med Interna 2000; 17 (12): 655-6.

5. Lopez Jimenez L. ¿Síndrome de hipertensión intratorácica o neumomediastino espontáneo? Med Clin 1999; 113 (4): 159.

cardiaco (signo de Hamman), presentes ambos en nuestro paciente. El diagnóstico se establece con la radiografía de tórax posteroanterior y lateral. El tratamiento es conservador dado que la resolución espontánea es la regla.

El neumomedistino espontáneo deberá considerarse en el diagnóstico diferencial del dolor torácico retroesternal en jóvenes asmáticos o tras maniobra de valsalva, esfuerzo físico o como en este caso tras respiraciones profundas; su diagnóstico es sencillo a través de la clínica, exploración física y radiografía de tórax y su tratamiento y seguimiento debe ser ambulatorio.

\section{B. Martínez Urroz, L. Marcos Primo, M. L. Pascual Martín, M. López Moreda}

Médicos Especialistas en Medi cina Familiar y Comunitaria. Centro de Salud Chopera I. Al cobendas. Madrid 